\title{
PORTUGAL: DO MEDITERRÂNEO AO ATLÂNTICO, NO SÉCULO XV
}

\author{
Humberto Baquero Moreno \\ Universidade Portugalense
}

Quando nasce o Infante D. Henrique em 4 de Março de 1394, seu pai o rei $D$. Joâo I encontrava-se a braços com graves problemas internos que importava resolver. Nas recém realizadas cortes de Coimbra, iniciadas em Dezembro do ano anterior, vêm ao de cima as enormes dificuldades com que se debatia $\circ$ reino em luta contra Castela, precisamente quando alguns procuradores concelhios, especialmente convidados, procediam ao juramento das tréguas firmadas com Castela em 13 de Maio de $1393^{(1)}$. Um dos problemas mais emergentes, numa crise generalizada consistia na necessidade por parte da coroa de recuperar muitas terras que haviam sido doadas na sequência da revolução e da necessidade de aliciar partidários, tendo como finalidade aumentar o património e constituir no futuro as casas de seus filhos, D. Duarte e D. Pedro, que entretanto haviam nascido.

Contra esta política insurgiu-se uma boa parte dos fidalgos que haviam apoiado o monarca, os quais aparecem liderados pelo condestável Nuno Álvares Pereira, o qual mostra o seu descontentamento, numa reuniâo em Estremoz, ao declarar expressamente a sua vontade de «hir fora do regno a buscar vidas ${ }^{(2)}$.

Esta atitude, num momento crucial da história portuguesa, causa sérios embaraços ao monarca, para além de outros conflitos que se traduzem, conforme se verifica nas cortes de Coimbra iniciadas em Dezembro de 1394 e concluídas em meados de Janeiro do ano seguinte, em inúmeras queixas que assentam essencialmente na desvalorizaçâo da moeda e na escassez de mâo de obra rural, a que se junta a exigência de salários elevados e a recusa do trabalhador em viver com indivíduos de condiçâo inferior ${ }^{(3)}$.

Em 1396 assiste-se a um súbito agravamento nas relações entre Portugal e Castela. O rei Henrique III é acusado de nâo respeitar as cláusulas assinadas em 15 de Maio de 1393. Como represália os portugueses tomam a iniciativa e ocupam Badajoz a 12 de Maio. Em 
resposta os castelhanos atacam e incendiam Viseu, o que suscita do nosso lado a mobilização de homens de guerra ${ }^{(4)}$.

Assume foros de gravidade o comportamento da nobreza que se recusa a ouvir o chamamento de guerra de D. Joâo I. Num rosário de queixas lamentam-se os fidalgos nas cortes efectuadas em Coimbra, no mês de Janeiro de 1398, que cada vez se vivia pior atendendo a que as rendas se encontravam desvalorizadas e que a moeda valia muito pouco. Queixam-se contra as restrições impostas pelo rei no direito de aposentadoria, nas dificuldades resultantes da oposição por parte dos homens bons dos concelhos no que respeita à aquisição de herdades e exigem a D. Joâo I que respeite os seus foros e costumes tal como já o fizera durante o cerco de Lisboa e as cortes de Coimbra de 1385. Apesar do confronto entre o rei e a nobreza, sente-se um apoio expresso por parte dos concelhos que concedem novos pedidos para a guerra contra Castela $^{(5)}$.

Determinado D. Joâo I no seu intento de readquirir terras, que outrora haviam sido do património da coroa, comprou-as a diversos fidalgos, com destaque para Martim Vasques da Cunha, Joâo Fernandes Pacheco, Lopo Fernandes Pacheco, Egas Coelho e João Gomes da Silva ${ }^{(6)}$.

Revoltados contra o monarca alguns destes fidalgos optaram pelo exílio em Castela. Fernão Lopes apenas menciona a saída de João Fernandes Pacheco e de Lopo Fernandes Pacheco e ainda de Gil Vasques da Cunha e João Afonso Pimentel. Contudo, sabemos, que no período compreendido entre 1397 e 1400 optaram pelo mesmo destino, Egas Coelho, Pero Coelho e Gomes Coelho, Vasco Machado e Martim Vasques da Cunha acompanhado por seu irmão Lopo Vasques da Cunha. A estes nobres deverá acrescentar-se Diogo Pires de Avelar, Álvaro Gonçalves Camelo, Fernando Afonso de Ulveira, Álvaro Coitado, João Taveira e Vasco Taveira ${ }^{(7)}$.

Em plena sangria da nobreza portuguesa surge no Porto, onde se encontrava o rei, o emissário de Henrique III de Castela, Ambrósio de Morines, com o propósito de negociar uma nova trégua ${ }^{(8)}$.

As tentativas para negociar a paz goraram-se e a confirmá-lo temos as cortes de Lisboa, reunidas em Agosto de 1399, precisamente com o objectivo, da parte da coroa, de se proceder ao lançamento de um novo pedido destinado a prosseguir a guerra contra Castela e enfrentar a desvalorização da moeda, estabelecendo para o efeito uma nova equivalência entre a moeda em curso $^{(9)}$.

Em 1400 a guerra desenvolve-se na fronteira com particular incidência, durante o mês de Maio, sobre o Crato e Valença de Alcântara $^{(10)}$.

Apesar de todas as dificuldades que Portugal atravessou devido às sucessivas guerras, a internacionalização do conflito, com particular intervenção da Inglaterra, trouxe até ao nosso País mercadores oriundos daquele reino e de países como a Flandres e Génova. O peso económico 
dos provenientes desses estados desenvolveu um movimento de xenofobia da parte dos homens de negócio da capital, os quais através dos seus procuradores às cortes de Guimarães, realizadas em Janeiro de 1401, protestavam contra a concorrência desleal desses súbditos estrangeiros, os quais arrendavam as rendas do pão e do vinho das igrejas com enormes lucros, sem que tivessem que suportar as despesas para a guerra contra Castela, tal como acontecia com os nacionais ${ }^{(11)}$.

Um passo importante no sentido de alcançar a paz com Castela foi dado durante as cortes celebradas em Santarém, no ano de 1402 , reunidas no mês de Março, nas quais se discutiu amplamente a prorrogação das tréguas com o reino vizinho ${ }^{\text {(12) }}$.

De forma a garantir a trégua com Castela o rei empenhou-se a fundo na reparação dos castelos que se encontravam arruinados, principalmente aqueles que se localizavam na raia. As preocupações do monarca foram apresentadas aos procuradores dos concelhos durante as cortes de Évora realizadas em Abril de 1408. Outro tema abordado que reflectia de igual modo o pensamento de D. Joâo I consistia na necessidade de se formarem as casas de seus filhos D. Duarte, D. Pedro e D. Henrique, para o que se solicitava um subsídio público, obtido a partir da cobrança de sisas, no valor de vinte contos anuais ${ }^{(13)}$.

Vai ser a paz com Castela, assinada em Ayllon, em 31 de Outubro de 1411, cuja validade manter-se-ia até Joâo II alcançar a maioridade em 1420 , o que irá permitir ao monarca português desenvolver os seus planos expansionistas em Marrocos. Um dos desideratos dos negociadores castelhanos visava o propósito de Portugal ficar obrigado a auxiliar o reino vizinho quando o mesmo se disponibilizasse a conquistar o reino de Granada. Contudo os emissários portugueses opuseram-se terminantemente a que esta cláusula ficasse contemplada no tratado, na medida em que a sua aceitação significaria uma submissão aos ditames da política externa do reino de Castela. Ficou, no entretanto, acordado que a rainha viuva de Henrique III, de Castela, solicitaria quando o necessitasse a ajuda de Portugal na conquista daquele reino muçulmano. Face à expectativa criada o rei $\mathrm{D}$. Joâo I actuou junto da rainha-regente de Castela no sentido duma campanha conjunta sobre Granada, tendo como resposta, da parte de $\mathrm{D}$. Catarina, que sendo ela muiher não poderia envolver-se numa expedição militar desta natureza. Também o rei de Aragão Fernando I mostrou-se indisponível alegando que o compromisso de Caspe, assinado em 15 de Junho de 1412, o impedia de imiscuir-se nos assuntos que pertenciam a Castela e que por conseguinte não agiria em relação ao reino granadino ${ }^{(14)}$.

Vinte e sete anos de hostilidades tinham gerado uma mentalidade favorável ao espírito de guerra. Eis a razão porque Zurara observa quando da assinatura da paz, que muitos fidalgos portugueses, pertencentes às camadas mais jovens não beneficiadas pela distribuição de benesses que se seguiram à revolução de 1383 , se mostravam contrários ao restabelecimento da concórdia, na medida em que a suspensão das 
hostilidades os prejudicava na obtenção de despojos de guerra arrancados ao inimigo ${ }^{(15)}$.

Encontrar uma resposta sobre as motivações profundas da nossa ida a Ceuta depara com bastantes dificuldades, o que aliás reforça a opinião de Robert Ricard acerca dos obstáculos existentes que permitam vislumbrar as verdadeiras causas. Dentro das questões que se colocam com alguma pertinência inquire-se se D. Joâo I, tal como afirma Zurara, teria procurado fornecer aos filhos, D. Duarte, D. Pedro e D. Henrique, a oportunidade de ganharem gloriosamente as suas esporas de cavaleiros ou seria antes seu propósito impedir a expansão de Castela em direcção ao Norte de África? Sabemos com base no cronista, que D. João I passou em revista, com extremo cuidado, os prós e os contras da empresa. Algumas dúvidas, contudo, devem ter sobressaltado o espírito do monarca. Conquistada a cidade seria possível conservá-la? Ao ser ocupada o benefício não viria a reverter em favor de Castela? ${ }^{(16)}$.

Em conformidade com o testemunho de Zurara, algumas mostras de prudência do rei desapontaram os filhos. Antes de preparar o ataque, 0 monarca usou o seguinte estratagema, com a finalidade de observar as condições de defesa da praça: enviou à Sicília dois embaixadores, pretextando o pedido de casamento da rainha com o infante $D$. Pedro, com a certeza de que o mesmo seria recusado. Durante a ida e o regresso, o navio fez escala em Ceuta e assim puderam observar de perto a sua estratégia defensiva ${ }^{(17)}$.

Zurara revela-nos que D. Filipa de Lencastre aprovou o projecto do marido. Conhecedora de que o destino era Ceuta e receando os perigos que ameaçavam o reino, caso falecessem $D$. Joâo $l$ e os seus filhos mais velhos, colocou como condição que os mais novos, os infantes D. Joâo e D. Fernando, permanecessem no reino. O monarca não consultou a nação em cortes, contrariamente ao estabelecido no parlamento de 1385 , determinado pela preocupação de guardar o maior segredo. Em princípio não podia lançar um novo imposto sem o consentimento dos procuradores dos concelhos. Para suprir esta limitação mandou apreender toda a prata e cobre e procedeu à cunhagem de moeda com novo valor facial ${ }^{(18)}$.

A nação estava preparada para a guerra. Ao colocar o problema ao conselho real D. Joâo I não enfrentou qualquer oposição. Todos em uníssono mostraram-se favoráveis à empresa. A expedição a Ceuta foi organizada com todos os cuidados e máxima eficácia. O conhecimento dos seus preparativos gerou o maior alarme entre os reinos da Península Ibérica, que se mostravam desorientados quanto ao destino da expedição. A testemunhar o embaraço temos as duas cartas enviadas pelo espião aragonês Rui Dias de Vega ao seu monarca Fernando I. Dois eram os palpites: Ceuta ou Gibraltar. Entre as diversas versōes dizia-se que seria enviada a Inglaterra, a infanta D. Isabel, acompanhada por seus irmãos, para se the negociar um casamento honroso. Para outros o que se pretendia era tratar do matrimónio da rainha viúva de Nápoles com alguns 
dos infantes. Outros, ainda, opinavam que se tratava duma romagem aos lugares Santos em sinal de agradecimento pela paz alcançada com Castela. Havia, ainda, quem colocasse a hipótese de um ajuste de contas com o duque de Holanda, cujos vassalos tinham cometido roubos sobre navios portugueses. Outras hipóteses mais dispares eram formuladas. Apenas um judeu, servidor da rainha D. Filipa, que entretanto havia enviado uma trovas ao escudeiro do infante D. Pedro, Martim Afonso de Atouguia, acertou em cheio, quando escreve «que os mais sesudos entendiam que el-rei iria sobre a cidade de Cepta ${ }^{(19)}$.

Em conformidade com o desejo expresso manifestado por $D$. Filipa, a frota largou do Tejo no dia de Santiago, 25 de Julho de 1415. A armada era constituída por mais de duzentos navios de guerra, transportando um contingente militar de cerca de vinte mil combatentes. A frota depois de dobrar o cabo de S. Vicente, fez escala em Lagos. Aqui o rei requereu ao seu capelão Frei João Xira, que expusesse as razões da expedição, tendo o religioso procedido naturalmente à pregação duma cruzada $^{(20)}$.

A cidade foi conquistada em 21 de Agosto de 1415. Reunido o conselho pelo monarca optou-se pela solução de a conservar em vez de a destruir. Depois de algumas divergências, entretanto sanadas, acordou-se a nomeação de D. Pedro de Meneses para o cargo de governador da praça com uma guarnição de dois mil e quinhentos homens. Zurara diz-nos que os marroquinos se opuseram com tenacidade à presença dos portugueses, tendo atacado Ceuta sem êxito com dura violência por duas vezes: nos anos de 1418 e $1419^{(21)}$.

Como explicar as razões da ida a Ceuta? Como bem sublinha Borges de Macedo «não havia razões imediatas, económicas ou religiosas, para a conquista de Ceuta. Foi até necessário consultar os teólogos sobre a sua legitimidade e a resposta não foi muito clara». No entender deste historiador as razões explicativas são outras e devem encontrar-se no equilíbrio das forças internacionais. Assim «a operação militar é o resultado duma estratégia» a qual «deriva directamente da insuficiência do apoio provável da Inglaterra a Portugal no século XV e tem em vista assegurar para Portugal uma maior área de intervenção, para o equilíbrio peninsular ibérico, de modo a poder agir como forma de pressão sobre Castela [...] e de valorização do reino aragonês no sul, ${ }^{(22)}$.

No entender deste autor «a presença dos cristãos em Marrocos tanto podia ajudar à conquista de Granada pelos castelhanos como aumentar a pressão militar que sobre eles se podia exercer, em caso de um ataque seu às extensas fronteiras portuguesas, como ainda facilitar a intervenção militar aragonesa numa área castelhana. Acrescente-se que Ceuta facultava uma posição de excepcional valor no estreito de Gibraltar, permitindo, enfrentar a pirataria que tanto prejudicava as comunicações Mediterrâneo-Atlântico». Além disso "a incerteza de poder contar com a ajuda de uma posição influente e determinante no mar do Norte explica esta marcha para o Mediterrâneo e a criação de um ponto de manobra 
que aumentasse a capacidade de intervenção diplomática e eventualmente militar, no equilíbrio peninsular» ${ }^{(23)}$.

Em 1419, no mês de Agosto, os marroquinos auxiliados pelo rei mouro de Granada cercam a cidade de Ceuta pelo espaço de cinco dias $^{(24)}$. Perante a gravidade da conjuntura D. Duarte e D. Pedro partiram para o Algarve em busca de reforços. Por seu lado D. Henrique e D. Joâo seguiram para aquela praça marroquina em meados de Setembro, tendo chegado ao destino em Outubro durante um novo assédio do rei de Granada, que teve de retirar ao fim de duas semanas de combate com pesadas perdas ${ }^{(25)}$.

Entretanto as relações entre Portugal e Castela iam-se agravando. O grupo de pressão favorável à guerra começou a predominar no Conselho Real de Castela, onde alguns dos conselheiros opinam que apenas seja concedida uma curta trégua com Portugal. O partido dos falcões chega a defender a tese de que se constitua uma frota de guerra e se forme um exército de oito mil lanças e trinta mil soldados de infantaria, que imponham respeito a Portugal. As negociações arrastam-se penosamente pelo espaço de três anos ${ }^{(26)}$.

A assinatura do tratado de paz entre os dois reinos veio a ser efectuada em Avila, a 30 de Abril de 1423, tendo pertencido a D. Joâo I a iniciativa de comunicar ao reino, por carta de 4 de Setembro a boa nova de que a paz seria válida até 6 de Março de $1434^{(27)}$.

Uma nova fase da expansão atlântica se inícia com a descoberta da ilha de Porto Santo, em 1418, por dois escudeiros do infante D. Henrique, Joâo Gonçalves Zarco (filho do vedor da fazenda Joâo Afonso) e Tristão Vaz Teixeira, que entretanto tinham obtido autorização para levarem a cabo a guerra de corso. Há quem defenda, contudo, a hipótese de alguns navegadores peninsulares terem conhecido o arquipélago madeirense pelo menos desde meados do século XIV. Oficialmente, porém, a descoberta da Madeira situa-se em $1419^{(28)}$.

D. Henrique desenvolve uma política que visa a conquista da Grão-Canária, a qual passa a estar integrada no âmbito do espaço atlântico português. Dentro desse objectivo organiza uma expedição dirigida pelo vedor da sua casa D. Fernando de Castro, o qual em 1424 pretende sem êxito proceder à sua ocupação. A ilha da Madeira começa a ser povoada em 1420, exploração que vem a intensificar-se cinco anos mais tarde. Uma nova tentativa de ocupação da Grão-Canária verifica-se em 1427 com Gonçalves da Câmara. Quanto às ilhas orientais dos Açores o início da sua descoberta parece apontar para 1427 com Diogo de Silves ${ }^{(29)}$.

Um passo importante no sentido da aproximação entre Portugal e o ducado de Borgonha dá-se, quando D. Joâo I assiste em Lisboa, em 24 de 1429 , ao contrato de procuração matrimonial entre sua filha $D$. Isabel e o duque Filipe o Bom ${ }^{(30)}$. É dentro deste contexto que o monarca se vê na contingência de realizar cortes em Santarém, durante o mês de Maio, para que se aprovasse a votação de um pedido e meio para pagamento ao 
duque de Borgonha do dote da infanta D. Isabel. Devido ao difícil estado em que se encontrava o tesouro público ficavam obrigados a este pagamento tanto o povo como o clero, apenas se exceptuando a nobreza. Ainda nestas cortes, com toda a probabilidade, deve-se ter iniciado a discussão tendente a encontrar uma solução para a assinatura da paz com Castela que viria a concretizar-se no ano seguinte ${ }^{(31)}$. De observar que o estreitamento da aliança com Aragão viria ao de cima com a realização em Coimbra, no mês de Setembro de 1428, das cerimónias nupciais entre o príncipe herdeiro D. Duarte e D. Leonor de Aragão, embora D. Joâo l estivesse ausente, alegando doença, havendo, contudo, motivos para suspeitar que não o fizesse por razões de incompatibilidade com seu filho, o infante D. Pedro, que o levaram a não voltar a Coimbra até o termo da sua vida em 14 de Agosto de $1433^{(32)}$.

Estando D. Joâo I em Montemor-o-Novo em 7 de Novembro de 1432, coube-lhe jurar perante os embaixadores castelhanos o tratado de amizade celebrado com o rei de Castela Joâo ${ }^{\left({ }^{(33)}\right.}{ }^{\text {. As cláusulas }}$ especiais do tratado de paz negociadas pelo príncipe $D$. Duarte no Sardoal, a 18 de Dezembro, foram confirmadas por seu pai, encontrando-se em Alcochete, no dia 26 de Dezembro do mesmo ano. A paz entre as duas nações tinha sido assinada em Medina del Campo em 30 de Outubro do ano anterior ${ }^{(34)}$.

A conjuntura interna em Castela propiciou o acordo de paz. O conflito que se travava entre os infantes de Aragão e o valido de João II, Álvaro de Lina, era de molde a fragilizar o poderio castelhano. Tendo um dos infantes, D. Joâo, ascendido a rei de Navarra (ano de 1425), o condestável de Castela achou prudente libertar Henrique de Aragão e devolver-lhe os bens. A acção conjugada desses infantes obriga de imediato Joâo II a ordenar em 1427 o desterro de D. Álvaro de Luna. As dificuldades encontradas coagiram a nobreza castelhana a apelar de novo para o valido do rei. Para contrabalançar a hegemonia dos Trastamaras que dominam os tronos peninsulares, Portugal negoceia em Setembro de 1428, o casamento do infante D. Pedro com a filha do conde de Urgel, D. Isabel, que se veria preterido em 1412, por Fernando de Antequera, nas suas aspirações ao trono de Aragão. Entretanto, em 1429, Afonso V de Aragão intervém em Castela em auxílio dos irmãos contra D. Álvaro de Luna. Temendo, no entanto, uma acentuada afinidade entre este e os infantes portugueses resolve desistir e procura a paz com o nosso reino. Portugal livra-se da pressão peninsular e opta pela sua vocação atlântica $^{(35)}$.

Depois da passagem do Bojador por Gil Eanes, em 1434, o infante D. Henrique pleno de entusiasmo determina a este escudeiro da sua casa, acompanhado de Afonso Baldaia, que prossiga na exploração da costa africana. Este navegador descobre em 1436 o rio do Ouro e a Pedra da Galé( ${ }^{(36)}$.

Se dúvidas não há quanto a um acordo generalizado no que respeita a uma exploração sistemática da costa africana, o mesmo não se 
pode afirmar em relação à política de expansão em África. A carta escrita pelo infante D. Pedro desde Bruges em 1425 a seu irmão D. Duarte, exprime algumas reservas em relação à nossa permanência em Ceuta, embora não seja suficientemente clara quanto à solução a empregar. Para o duque de Coimbra a cidade de Ceuta representa um "bom sumidoiro de gente de vossa terra e d'armas e de dinheiro" ${ }^{(37)}$.

Antes, porém, de nos abalançarmos na problemática da expansão em Marrocos, convém reflectir um pouco sobre a capacidade naval e militar de Portugal.

$\mathrm{Na}$ expedição a Ceuta participaram, conforme se viu acima, duzentos navios grandes e pequenos e à volta de vinte mil homens. Este contingente parece representar o maior esforço naval e militar de Portugal. Embora a dimensão dos navios fosse variável deparamos com uma média aritmética de cem homens por nau. Este valor encontra-se próximo das estimativas de Brian Tate que avalia a capacidade média de transporte por navio em sessenta homens ${ }^{(38)}$.

A partir do reinado de $D$. Dinis, Portugal intensifica o seu comércio marítimo com Aragão, França, Bretanha, Flandres e Inglaterra, empregando-se barcas de 100 tonéis. A legislação fernandina de 1377 procurou por todos os meios estimular o aumento da capacidade de tonelagem, embore se julgue com pouco êxito. A expedição a Ceuta impulsionou a construção naval. No que toca ao Porto esta cidade contribuiu com setenta naus e barcas e "muita fustalha» ou seja barcos a remos $^{(39)}$.

Desde o século XIII aparecem-nos referências às barcas utilizadas no carreto de mercadorias. Eram de pequenas dimensões, movendo-se a remos, embora algumas navegassem à vela. Sabe-se, contudo, que se empregavam em Portugal na navegação de cabotagem e mesmo nas relações comerciais com outros países ${ }^{(40)}$.

De maior dimensão era o barinel que explorava a costa africana, cuja capitania pertencia ao mencionado Afonso Baldaia, enquanto Gil Eanes navegava com uma barca. Era um barco à vela, muito embora pudesse utilizar os remos ${ }^{(41)}$.

Por seu turno a caravela, empregava velame latino, com um, dois ou três mastros, tendo o porte de cinquenta tonéis. Era um navio ágil e facilmente manobrável, embora com reduzida tripulação. Tanto as caravelas Mexia, como a Godinho, apenas transportavam o máximo de vinte e cinco tripulantes, embora habitualmente esse número fosse inferior $^{(42)}$.

Uma estimativa dos recursos militares resulta bastante aleatória na medida em que no período analisado não existe um exército permanente e profissionalizado. Se bem é certo que todo o nobre é um militar, em termos aproximados o conhecimento duma centena de estirpes deverá traduzir-se num total de três mil pessoas nobilitadas pertencentes aos diversos escalões da nobreza. Os próprios corpos militarizados assentando no regimento dos besteiros do conto exprime uma acentuada 
irregularidade na medida em que o seu valor médio se situa em cerca de cinco mil homens repartidos pelo reino. A inconstancia no que respeita à manutenção de espécies equinas obsta ao estabelecimento dum número médio de coudéis equivalente ao dos besteiros do conto ${ }^{(43)}$.

A formação dos exércitos depende essencialmente das necessidades emergentes. Durante o conflito que desembocou na batalha de Alfarrobeira o exército real de acordo com o computo, um tanto ou quanto exagerado de Rui de Pina era formado por trinta mil combatentes, valor que Gaspar Dias de Landim reduz aleatoriamente para pouco mais de metade. O número de cavaleiros andaria pelos cinco mil integrando os restantes a peonagem, cujo valor médio se deverá aproximar dos vinte mil homens, dos quais um milhar seria constituído por homiziados abrangidos pela amnistia concedida por $\mathrm{D}$. Afonso $\mathrm{V}$. De notar que a artilharia e o seu manuseamento se encontrava confiada a bombardeiros alemães possuidores duma elevada preparação tecnológica. O exército ducal pertencente a $\mathrm{D}$. Pedro situava-se, de acordo com Rui de Pina, num total de mil cavaleiros e cinco mil peões. Globalmente em campo de batalha teriam estado envolvidos entre trinta a trinta e cinco mil homens, o que numa população de um milhão de habitantes corresponde a uma percentagem inferior a $5 \%$ de homens em estado de guerra, hetero-geneamente armados e preparados para o combate ${ }^{(44)}$.

Os escassos recursos militares do País explicam muitas das dúvidas que se colocam em relação a uma intervenção militar em Marrocos. Uma das vozes mais contrárias foi a do conde de Arraiolos, que em parecer dirigido ao rei D. Duarte, em 1433, opina que uma nova expedição a África seria um sério risco, lembrando a propósito que a guarnição militar de Ceuta representava um gasto inútil em homens e dinheiro. Apontava como alternativa uma ida a Granada. Em sintonia com este parecer temos o de seu pai, conde de Barcelos, que exprime o seu total desacordo ao lembrar que a mobilização de soldados e a requisição de barcos aos mercadores desencadeia ódios e ressentimentos $^{(45)}$.

O único aderente entusiasta duma ida a Tanger é o infante D. Henrique, que num parecer elaborado em 1436 defende que os portugueses tem o dever de partir para África, mesmo à custa dos maiores sacrifícios. Perante as divisões e no meio das contradições o rei D. Duarte convoca as cortes de Évora de 1436, onde lembra à opinião pública que prometera a seu pai, D. Joâo I, concretizar a expedição militar a Tanger. Antes, contudo, de se abalançar a esta empresa, o monarca ouviu seus irmãos D. Pedro e D. Joâo, que se mostram desfavoráveis ao empreendimento. $O$ duque de Coimbra afirma que a conquista de Tanger apenas será válida se for acompanhada duma intensa colonização. No seu parecer considera que o reino se encontra insuficientemente povoado e mal arroteado, estando a fazenda depauperada de recursos ${ }^{(46)}$. 
Por esta altura a igreja vivia uma grave crise. O conflito entre o papa e o concilio de Basileia desenrolava-se em ritmo acelerado, excomungando-se ambos os lados reciprocamente. É eleito o anti-papa Félix. O partido do papa de Roma, Eugénio IV entretanto triunfa. O bispo de Viseu, D. Luis Amaral é deposto por ter apoiado os conciliaristas. Irritado o papa Eugénio IV repreende o regente D. Pedro por ter apoiado a causa conciliarista ${ }^{(47)}$.

É precisamente neste quadro de crise que se assiste em 1437 ao desastre de Tanger. O rei D. Duarte não poupa D. Henrique, criticando a sua inépcia militar. Nas cortes de Leiria, iniciadas em 25 de Janeiro e concluídas em 6 de Fevereiro, o rei procura uma solução face à prisão de seu irmão D. Fernando, que entretanto the escrevera a solicitar-lhe a entrega de Ceuta em troco da sua libertação ${ }^{(48)}$.

No seio da conselho de Leiria detectam-se as contradições da sociedade portuguesa, sobretudo no que respeita aos rumos da expansão. Enquanto D. Pedro e D. Joâo preconizam a entrega de Ceuta, o arcebispo de Braga D. Fernando da Guerra exprime uma posição diferente, ao fazer depender da autorização da Santa Sé a sua devolução. O conde de Barcelos e seus filhos os condes de Arraiolos e de Ourem manifestam a sua total oposição. Na entrevista havida entre o rei e $\mathrm{D}$. Henrique, em Portel, o mestre da Ordem de Cristo opõe-se à entrega, chegando a oferecer-se em troca com o irmão cativo ${ }^{(49)}$.

A morte de D. Duarte ocorrida em 9 de Setembro de 1438 abre uma grave crise política. Aberto o testamento do falecido monarca passa a ser conhecido o seu desejo de que $\mathrm{D}$. Leonor exerça o cargo de regente enquanto $D$. Afonso $V$ não perfizer os catorze anos em 15 de Janeiro de 1446. De notar que a nobreza portuguesa liderada pelo conde de Barcelos e pelo arcebispo de Lisboa $D$. Pedro de Noronha apoia a viúva do rei convencida que as limitações patrimoniais impostas pela Lei Mental pudessem ser drasticamente diminuidas. $O$ infante $D$. Pedro é encarado como um acérrimo aliado de D. Álvaro de Luna na luta conjunta contras os nobres. O duque de Coimbra conta com o apoio solidário de seus irmãos, D. Henrique e D. Joâo, além da adesão da cidade de Lisboa, apoiada expressamente por setenta e duas cidades e vilas do País ${ }^{(50)}$.

O golpe de estado perpetrado por $D$. Pedro em 31 de Outubro de 1439 não significa necessariamente que o duque de Coimbra fique refém dos representantes urbanos. Esta atitude observa-se inclusivé nas cortes realizadas em Lisboa, em Dezembro desse ano, onde se observam, apesar das concessões em benefício da capital, algumas assintonias. Carece, assim, de fundamento a asserção de Luis Filipe Thomaz quando afirma que "as páginas da chancelaria que no início do reinado de $D$. Duarte estavam repletas de mercês aos grandes, passam a abundar em concessões aos concelhos" ${ }^{(51)}$.

A união que se regista entre os infantes de Portugal resulta da imperiosa necessidade de impedir um ataque dos irmãos de D. Leonor, ao mesmo tempo que o povo reunido em torno de $D$. Pedro vê nele o 
opositor à política de expansão territorial em África e á intensificação da exploração do Atlântico ${ }^{(52)}$.

Efectivamente, D. Henrique contou com o apoio do seu irmão o regente, na política atlântica. Assim, em 1441, o duque de Viseu envia Antão Gonçalves, com mais 21 homens, com destino ao rio do Ouro. Por sua vez Nuno Tristão atinge o Cabo Branco. Desde os fins de 1443, encontramos a D. Henrique com maior assiduidade em Lagos. A testemunhar o comprometimento do regente, este refere em carta de 22 de Outubro de 1443, que depois da descoberta do Bojador em 1434, os navios henriquinos haviam efectuado quinze viagens, das quais se procederá à elaboração de cartas de marear. Em 1444 Gonçalo de Sintra morre ao pretender negociar a entrega de escravos, dos quais duas centenas foram repartidos no ano anterior em Lagos. Outras descobertas foram efectuadas tendo em 1446, Álvaro Fernandes, ultrapassado em 110 léguas o Cabo Verde. A exploração de 198 léguas da costa africana durante o governo de oito anos e meio de D. Pedro, em contraste com as 94 léguas exploradas durante os restantes doze anos e meio que se estendem até à morte de D. Henrique em 1460, parece ser suficientemente ilustrativa ${ }^{(53)}$.

A oposição de D. Pedro à alienação do património da coroa em benefício da nobreza aumenta significativamente o número dos seus inimigos. Assim, quando $\mathrm{D}$. Afonso $\mathrm{V}$ alcança a maioridade 0 antigo regente começa a perder terreno. A brutal reacção da nobreza, com acusações infundadas, conduz o duque de Coimbra ao drama de Alfarrobeira, em 20 de Maio de 1449 , onde os seus partidários se vêem confrontados com a confiscação de seus bens e a perda dos seus direitos civícos, cuja reparação apenas resultaria com a concessão de cartas de perdão e a amnistia geral de $1455^{(54)}$.

No plano internacional Portugal vê-se politicamento isolado. D. Afonso $\mathrm{V}$ é violentamente criticado pelos duques de Borgonha, por Joâo II de Castela e pelo papa Nicolau V. O avolumar das tensões internas vem ao de cima com o assalto à Judiaria Grande de Lisboa e com a instauração dum clima de guerra civil. Contudo, no plano internacional a diplomacia portuguesa soma vitórias com o casamento da irmã do rei, Dona Leonor, com o imperador Frederico III, realizado em 1451, e de Henrique IV com D. Joana, também irmã de D. Afonso V, em $1455^{(55)}$.

A presença em Portugal de poderosas famílias de mercadores genoveses cuja actividade comercial permite estabelecer intensas relações entre o nosso País e o Mediterrâneo, aparece testemunhada pela presença de famílias como a dos Lomellini, cujos interesses se estendem à Flandres. Outros italianos que aparecem documentados são os prazentins, os milaneses, os florentinos e os venezianos ${ }^{(56)}$.

A grande expansão do comércio português no Mediterrâneo verifica-se a partir da segunda metade do século $X V$, em conformidade com as directrizes emanadas a partir de D. Afonso $\mathrm{V}^{(57)}$. 
Um importante documento que pude revelar em 1972 mostra-nos que navios portugueses transportavam mercadorias desde o Norte da Europa até à Itália. Sucede esta situação com o navio Santa Clara, propriedade do conde de Barcelos, que foi apressado entre Branhas e Barcelona, em 11 de Janeiro de 1440, quando transportava com destino a Génova diversas mercadorias pertencentes a mercadores portuenses e cuja proveniência pela natureza da carga parece indiciar que são artigos originários da Flandres e da Alemanha. $\mathrm{Na}$ descrição da carga surgem-nos artefactos no valor de quatro mil florins, onde se incluíam bombardas, armas, canhões, tapetes e colchas ${ }^{(58)}$.

Também em meados do século XV o cidadão portuense Afonso Dias, navegava no Mediterrâneo ao serviço do duque de Borgonha e outros casos semelhantes podem ser aduzidos ${ }^{(59)}$.

Apesar das graves dificuldades económicas que se vivem em Portugal, devido sobretudo aos excessos da coroa, D. Afonso V aparece-nos vocacionado para uma política africana, tudo parecendo indicar que o seu principal mentor foi $D$. Henrique como representante dos interesses da nobreza cujo património ia crescendo, com bruscos aumentos nas vésperas das operações militares ${ }^{(60)}$.

De facto, com o pleno advento de $\mathrm{D}$. Afonso $\mathrm{V}$ ao poder, o mestre da Ordem de Cristo viu-se contemplado com inúmeras doações. Passou a acumular o seu mestrado com o de Avis, retirado a seu sobrinho o condestável D. Pedro, pese embora o não reconhecimento da Santa Sé. Em 1454 o rei fez-Ihe dádiva, a titulo vitalício, de todas as terras que os seus navios tivessem descoberto desde o Cabo Não. Sintomática era a bula de Nicolau $V$, que outorgava todos os direitos de posse a $D$. Henrique sobre as terras e mar africanos desde o Bojador até à Guiné(61).

Em 1458 a esquadra portuguesa constituída por noventa e três navios rumou para Alcácer-Ceguer, praça forte que podia contar com o apoio de Ceuta. D. Afonso V entrou na cidade em 24 de Outubro, seguido pelo infante $D$. Henrique. $O$ desastre que provocava em homens e mantimentos a presença de guarnições militares nessa praça e em Ceuta gerou uma forte contestação à política africana do rei, que teve entre os seus opositores D. Pedro, filho do falecido regente, D. Fernando, irmão do monarca, e do próprio D. Duarte de Meneses, que à frente da fortaleza recém-conquistada teve de suportar o forte assédio do rei de $\mathrm{Fez}^{(62)}$.

Em 1460 o nosso País passa a ser objecto duma acentuada pressão, tanto de Castela como de Aragão para o estabelecimento duma sólida aliança com Henrique IV e com Joâo II. A aproximação de Portugal a Aragão depara com o oposição de Castela, que vê neste aproximar um grave perigo. O rei de Castela procede à feitura de jogo duplo ao alimentar a ambiguidade com Portugal quando negoceia o casamento de Carlos de Viana com Isabel a Católica, precisamente pouco antes de tratar do consórcio daquele príncipe com uma princesa portuguesa. Assim, a estratégia de $D$. Afonso $V$ de penetração no Mediterrâneo sofre um rude golpe, não obstante a intensificação da presença naval portuguesa. 
Enquanto a marinha portuguesa transporta produtos tropicais para 0 Mediterrâneo, envia produtos mediterrânicos para o Norte da Europa, contribuindo poderosamente para o estabelecimento duma rede cada vez mais apertada no domínio dos circuitos comerciais. 
$$
\text { . }
$$ 


\section{NOTAS}

1. Vereações (anos de 1390 - 1395), Porto, s./d., pp.211-231.

2. Fernão Lopes, Crónica de D. Joâo I, vol.II, Porto, 1983, cap.CLII-CLIII, pp. 332-336.

3. Maria Teresa Campos Rodrigues, "Cortes de Coimbra de 1394", in Dicionário de História de Portugal, vol.IV, Lisboa, 1971, p.401.

4. Fernão Lopes, ob. cit., vol.II, cap. CLVII e CLIX, pp. 342-345 e 347-349.

5. Ordenações Afonsinas, Coimbra, 1786, titulo 59, pp. 339-370. Cf. Iria Gonçalves, Pedidos e empréstimos públicos em Portugal durante a ldade Média, Lisboa, 1904, p. 207.

6. Humberto Baquero Moreno, "Contestação e oposição da nobreza portuguesa ao poder político nos finais da Idade Média", in Revista da Faculdade de Letras, vol.IV, Porto, 1987, p. 106.

7. Idem, Ibidem, p. 106 e seg.

8. Fernão Lopes, ob. cit., vol.Il, cap. CLXXVI e CLXXVII, pp.388-393.

9. A.H. de Oliveira Marques, "Cortes de Lisboa (1399)", in Dicionário de História de Portugal, vol.Il, Lisboa, s./d., pp. 759-760.

10. Humberto Baquero Moreno, Os Itinerários de El-Rei Dom Joâo I, Lisboa, 1988, p. 85.

11. Joaquim Veríssimo Serrão, "Cortes de Guimarães (1401)", in Dicionário de História de Portugal, vol.II, Lisboa, s./d., pp. 402-403.

12. Marcelo Caetano, "Subsídios para a história das cortes medievais portuguesas", in Bracara Augusta, vol. XIV-XV, Braga, 1964, p. 157.

13. Joaquim Veríssimo Serrão, Cortes de Évora (1408), vol.II, Lisboa, s./d., p. 150.

14. Luís Filipe Thomaz, De Ceuta a Timor, Viseu, 1994, pp. 59-60.

15. Gomes Eanes de Zurara, Crónica da tomada de Ceuta, Lisboa, 1915, cap.VI, pp. 19-22.

16. Humberto Baquero Moreno, "O valor da Crónica de Zurara sobre a conquista de Ceuta", in A Abertura do Mundo, in Homenagem ao Prof. Luís de Albuquerque, Lisboa, 1987, pp. 191-192.

17. Idem, Ibidem, p. 192.

18. Idem, Ibidem, p. 193.

19. Gomes Eanes de Zurara, ob. cit., cap.XXX, pp. 90-93.

20. Idem, Ibidem, cap. XIV, pp. 138-140.

21. Humberto Baquero Moreno, ob. cit., p. 196.

22. Jorge Borges de Macedo, História Diplomática Portugesa, Constantes e Linhas de Força, Lisboa, 1987, pp. 42-43. 
23. Idem, Ibidem, p. 43.

24. Gomes Eanes de Zurara, "Crónica de D. Pedro de Menezes", in Collecção de Livros Inéditos de História Portugueza, vol.II, Lisboa, 1972, cap. LXII, p. 418.

25. Idem, Ibidem, cap. LXXX, p. 474.

26. Luís Filipe Thomaz, ob. cit., p. 71.

27. Luis Suárez Fernández, Relaciones entre Portugal y Castilla en la época del Infante Don Enrique, Madrid, 1960, pp. 179-181.

28. Idem, Ibidem.

29. Humberto Baquero Moreno, "O infante D. Henrique: uma vida de descobrimentos", in Jornal de Notícias, 4 de Março de 1994, p. 13.

30. Idem, Ibidem.

31. Visconde de Santarém, Quadro Elementar, vol.III, Lisboa, 1846, pp. 69 e seg.

32. Maria Teresa Campos Rodrigues, "Cortes de Santarem (1430)", in Dicionário de História de Portugal, vol.III, Lisboa, 1968, pp. 767-768.

33. Monumenta Henricina, vol.III, Coimbra, 1961, doc. 125, p. 255.

34. Idem, vol.IV, doc. 43, pp. 167-170.

35. Idem, vol.IV, doc. 53, pp. 208-210.

36. Luís Filipe Thomaz, ob. cit., pp. 77-79.

37. Humberto Baquero Moreno, O Infante D. Henrique, p. 15.

38. Monumenta Henricina, vol. III, doc. 71, pp. 140 e seg.

39. "Las peregrinaciones marítimas medievales desde las islas Británicas a Compostela", in Santiago, Camino de Europa, Santiago de Compostela, 1993, p. 164.

40. Quirino da Fonseca, Os navios do Infante D. Henrique, Lisboa, 1958, pp. 16-17.

41. Idem, Ibidem, pp. 24-25.

42. Idem, Ibidem, p. 40.

43. Idem, Ibidem, pp. 47 e 83.

44. Humberto Baquero Moreno, "Alguns aspectos das cidades medievais. Os corpos militares e a demografia" in, Actas dos 150 anos do nascimento de Alberto Sampaio, Guimarães, 1995, pp. 293 e seg.

45. Humberto Baquero Moreno, A batalha de Alfarrobeira. Antecedentes $e$ Significado Histórico, Lourenço Marques, 1973, pp. 420 e seg.

46. Humberto Baquero Moreno, "A situação política em Portugal nos fins da Idade Média e os seus reflexos na expansão ultramarina", in Arquipelago, vol. XI, Ponta Delgada, 1989, p. 53.

47. Idem, Ibidem, pp. 54-55. 
48. Monumenta Henricina, vol.VII, Coimbra, 1965, doc. 83-86, pp. 117-131. 49. Domingos Mauricio Gomes dos Santos, $D$. Duarte e as responsa-bilidades de Tanger, (1433-1438), Lisboa, 1960, pp. 65-66.

50. Humberto Baquero Moreno, A situação política em Portugal..., p. 55.

51. Ob. cit., p. 106.

52. Humberto Baquero Moreno, A situação política em Portugal..., p. 56.

53. Humberto Baquero Moreno, O Infante D. Henrique, p. 16.

54. Humberto Baquero Moreno, A situação política em Portugal..., p. 57.

55. Idem, Ibidem, p. 58.

56. Virgina Rau, "Uma família de mercadores italianos em Porgual no século XV, os Lomellini", in Estudos de História, Lisboa, 1968, pp. 13-57.

57. Jacques Heers, "L'expansion maritime portugaise à la fin du Moyen Age: la Méditerranée", in Revista da Faculdade de Letras, tomo XXII, Lisboa, 1956, p. 9.

58. Humberto Baquero Moreno, "Cartas do Infante D. Pedro aos Conselheiros de Barcelona", in Arquivos do Centro Cultural Português, vol. IV, Paris, 1972, pp. 19-20 e 29-30.

59. Luís Adão da Fonseca, Portugal entre os mares, Madrid, 1993, p. 167.

60. Humberto Baquero Moreno, A situação politica em Portugal..., p. 58.

61. Humberto Baquero Moreno, $O$ Infante D. Henrique..., p. 16.

62. A. G. da Rocha Madahil, A política de D. Afonso V apreciada em 1460 , Coimbra, 1931, pp. 14 e seg. 